\title{
Social differences in avoidable mortality between small areas of 15 European cities: an ecological study
}

Rasmus Hoffmann 1*, Gerard Borsboom', Marc Saez ${ }^{2,3}$, Marc Mari Dell'Olmo ${ }^{3}$, Bo Burström ${ }^{4}$, Diana Corman ${ }^{4}$, Claudia Costa ${ }^{5}$, Patrick Deboosere ${ }^{6}$, M Felicitas Domínguez-Berjón ${ }^{7}$, Dagmar Dzúrová ${ }^{8}$, Ana Gandarillas ${ }^{7}$, Mercè Gotsens ${ }^{3}$, Katalin Kovács ${ }^{9}$, Johan Mackenbach ${ }^{1}$, Pekka Martikainen ${ }^{10}$, Laia Maynou ${ }^{2,3,11}$, Joana Morrison ${ }^{12}$, Laia Palència $^{3}$, Gloria Pérez ${ }^{12}$, Hynek Pikhart ${ }^{12}$, Maica Rodríguez-Sanz ${ }^{13}$, Paula Santana ${ }^{5}$, Carme Saurina ${ }^{2,3}$, Lasse Tarkiainen ${ }^{10}$ and Carme Borrell ${ }^{13}$

\begin{abstract}
Background: Health and inequalities in health among inhabitants of European cities are of major importance for European public health and there is great interest in how different health care systems in Europe perform in the reduction of health inequalities. However, evidence on the spatial distribution of cause-specific mortality across neighbourhoods of European cities is scarce. This study presents maps of avoidable mortality in European cities and analyses differences in avoidable mortality between neighbourhoods with different levels of deprivation.
\end{abstract}

Methods: We determined the level of mortality from 14 avoidable causes of death for each neighbourhood of 15 large cities in different European regions. To address the problems associated with Standardised Mortality Ratios for small areas we smooth them using the Bayesian model proposed by Besag, York and Mollié. Ecological regression analysis was used to assess the association between social deprivation and mortality.

Results: Mortality from avoidable causes of death is higher in deprived neighbourhoods and mortality rate ratios between areas with different levels of deprivation differ between gender and cities. In most cases rate ratios are lower among women. While Eastern and Southern European cities show higher levels of avoidable mortality, the association of mortality with social deprivation tends to be higher in Northern and lower in Southern Europe.

Conclusions: There are marked differences in the level of avoidable mortality between neighbourhoods of European cities and the level of avoidable mortality is associated with social deprivation. There is no systematic difference in the magnitude of this association between European cities or regions. Spatial patterns of avoidable mortality across small city areas can point to possible local problems and specific strategies to reduce health inequality which is important for the development of urban areas and the well-being of their inhabitants.

Keywords: Avoidable mortality, Health inequality, Small area, Urban health, Spatial analysis, Bayesian methods

\footnotetext{
* Correspondence: r.hoffmann@erasmusmc.nl

'Department of Public Health, Erasmus Medical Center, P.O. Box 2040,

Rotterdam, CA 3000, The Netherlands

Full list of author information is available at the end of the article
} 


\section{Background}

The concept of mortality amenable to medical care was introduced in the early 1970 s by Rutstein. His working group selected over 90 conditions as "sentinel health events" from which disease, disability or death "should not occur in the presence of timely and effective care" [1]. Revisions of the aforementioned list undertaken in 1977 and 1980 [2,3] have formed the basis for practically all subsequent studies on avoidable mortality. Charlton was the first to apply the concept at the population level in England and Wales in 1974-78, also introducing the terms "avoidable deaths" and "conditions amenable to medical intervention" [4]. He narrowed the concept by excluding deaths that were not directly linked to medical care, e.g. deaths avoided by policies on tobacco control, and the concept was developed further within the Health Services Research Program of the European Community in the 1980s. This collaborative action resulted in a European Community atlas of avoidable mortality in which the work of Charlton and colleagues was extended and the boundaries of health services were interpreted as encompassing primary care, hospital care and collective health services [5]. In 2001 Tobias and Jackson produced an updated list of conditions derived from an expert consensus exercise in which the relative avoidability of death was distributed according to primary, secondary and tertiary actions [6].

The usefulness of the concept of avoidable mortality is based on the assumption that such causes of death are related to the functioning of medical care. This association has been studied in the past [7-9]. Avoidable causes of death can point at possible deficiencies in the delivery of medical care. Although their direct and simple use as indicators of quality of medical care in international comparisons is questionable [10], avoidable mortality represents the fraction of overall mortality that is more responsive to medical interventions and therefore offers insights into the scope for improvement of medical care. The link between the concept of avoidable mortality and research on health inequalities is based on the fact that medical care plays a role for the origin and reduction of socioeconomic inequalities in health and mortality $[11,12]$. The latter can be explained by differences in access and use of medical care by socioeconomic group [13]. Therefore the analysis of socioeconomic differences in avoidable causes of death can offer important lessons for tackling health inequalities. Following this reasoning, studies have looked at social differences in avoidable mortality [14] and whether access to medical care explains socioeconomic differences in avoidable mortality [15].

We combine the avoidable mortality approach with an analysis of mortality on the small area level because the socio-spatial context of the small area has been shown to be an important determinant of health and health inequality that goes beyond the effect of individual characteristics on health. This socio-spatial epidemiological framework has been proposed on the general conceptional level of "place" as a determinant of health $[16,17]$, on the more specific level of the city $[18,19]$, but also on the small area level as unit of analysis [20]. Studying health inequalities in small city areas is useful because, first, the percentage of urban population is increasing [19], second, health inequalities tend to be larger in cities than in rural areas because city areas tend to contain a concentration of deprivation, poverty or affluence, and third, some policies and interventions aiming at the reduction of health inequalities are approved and implemented at the city level. Therefore the monitoring of and intervening on health inequalities and its determinants at the city and small area level are especially appropriate [21]. For these reasons the use of spatial analysis of health outcomes and their predictors have been increasing in the past years. Likewise, the development of spatial methods for epidemiological analysis has rapidly improved $[22,23]$.

In principal, the link between the socio-spatial concept of health determinants and avoidable mortality has been already established by studies observing geographical variations of avoidable mortality $[4,24]$ but very few studies have applied this concept to the level of small areas $[25,26]$. While mortality differences in small areas of Spanish cities are relatively well studied [25,27], studies showing geographical patterns of socioeconomic indicators and cause-specific mortality by small area in a large number of European cities are scarce and no study has used avoidable mortality for such a comparison on an international scale. This is the first study presenting spatial patterns of avoidable mortality in small areas of several cities of different European countries and its dependence on area-level social deprivation.

We have studied 14 avoidable causes of death, first, to estimate smoothed Standardised Mortality Ratios (SMR) for the small areas of 15 European cities in the early 21 th century by gender, and to represent them on maps and, second, to estimate inequalities in the level of avoidable mortality between small areas with different level of deprivation.

In this paper we analyse (1) whether levels of mortality from avoidable causes of death are higher in deprived small areas and (2) whether the magnitude of these social inequalities in mortality differs between European cities, regions and gender.

\section{Results}

Table 1 gives an overview of the cities in our study, their number of small areas with at least one inhabitant, and illustrates our data on the study population, on mortality and on the distribution of social deprivation in percentiles. 
Table 115 European cities, number and size of their areas, period of mortality, number of deaths, and distribution of social deprivation

\begin{tabular}{|c|c|c|c|c|c|c|c|c|c|c|c|c|c|c|c|c|c|}
\hline \multirow[t]{3}{*}{ City } & \multirow{3}{*}{ N. of areas } & \multicolumn{9}{|c|}{ Population } & \multicolumn{4}{|c|}{ Mortality } & \multirow{2}{*}{\multicolumn{3}{|c|}{$\begin{array}{c}\text { Deprivation index } \\
\text { Both gender }\end{array}$}} \\
\hline & & \multirow[t]{2}{*}{ Year } & \multicolumn{4}{|c|}{ Men } & \multicolumn{4}{|c|}{ Women } & \multirow[t]{2}{*}{ Period } & \multicolumn{3}{|c|}{ Number of avoidable deaths ${ }^{a}$} & & & \\
\hline & & & Total & P25 & P50 & P75 & Total & P25 & P50 & P75 & & Men & Women & Total & P25 & P50 & P75 \\
\hline Amsterdam & 94 & 2001 & 363,877 & 1630 & 3768 & 5,551 & 374,448 & 1674 & 3826 & 5766 & 1996-2008 & 6224 & 9044 & 15268 & 4.26 & 6.45 & 8.79 \\
\hline Barcelona & 1491 & 2004 & 750,998 & 364 & 457 & 578 & 837,406 & 421 & 517 & 648 & $1996-2008$ & 21,875 & 30,947 & 52,822 & 5.61 & 6.99 & 8.75 \\
\hline Bratislava & 17 & 2004 & 198,778 & 1138 & 8927 & 16,230 & 226,378 & 1216 & 9795 & 18,360 & $1996-2008$ & 4329 & 4764 & 9093 & 3.94 & 4.52 & 4.85 \\
\hline Brussels $^{\mathrm{b}}$ & 118 & 2001 & 464,364 & 2604 & 3763 & 5089 & 505,673 & 2958 & 4020 & 5742 & $2001-2004$ & 2022 & 3400 & 5422 & 5.51 & 7.13 & 9.29 \\
\hline Budapest & 23 & 2004 & 776,834 & 26,010 & 35,590 & 41,690 & 928,475 & 32,380 & 41,140 & 49,410 & $2001-2008$ & 17,187 & 24,981 & 42,168 & 5.48 & 6.41 & 6.97 \\
\hline Helsinki & 94 & 2004 & 250,567 & 1410 & 2351 & 3642 & 292,134 & 1524 & 2681 & 4368 & $2000-2009$ & 2571 & 4335 & 6906 & 3.58 & 4.55 & 5.31 \\
\hline Košice & 22 & 2004 & 112,275 & 598 & 1632 & 10,370 & 122,966 & 647 & 1741 & 11,820 & 1996-2008 & 2216 & 2492 & 4708 & 5.71 & 6.51 & 7.68 \\
\hline Lisbon $^{c}$ & 207 & 2001 & $1,275,659$ & 1959 & 4558 & 8278 & $1,386,191$ & 2135 & 5065 & 9428 & $1995-2008$ & 46,337 & 55,548 & 101,885 & 4.89 & 5.76 & 6.41 \\
\hline London $^{d}$ & 633 & 2001 & $3,468,738$ & 4835 & 5460 & 6194 & $3,703,293$ & 5177 & 5827 & 6582 & $1995-2008$ & 57,685 & 81,638 & 139,323 & 6.26 & 7.80 & 9.68 \\
\hline Madrid & 2358 & 2005 & $1,481,721$ & 459 & 576 & 724 & $1,667,894$ & 531 & 663 & 807 & 1995-2007 & 32,979 & 45,665 & 78,644 & 5.56 & 7.83 & 9.75 \\
\hline Prague & 57 & 2004 & 559,108 & 912 & 1875 & 13,320 & 611,463 & 906 & 1575 & 13,890 & 2003-2007 & 5617 & 7950 & 13,567 & 4.25 & 4.37 & 4.54 \\
\hline Rotterdam & 83 & 2001 & 294,398 & 417 & 3276 & 5466 & 305,624 & 414 & 3260 & 5273 & 1996-2008 & 6047 & 9347 & 15,394 & 4.90 & 6.71 & 9.24 \\
\hline Stockholm & 1171 & 2004 & 914,257 & 249 & 596 & 1070 & 950,102 & 257 & 628 & 1132 & $2000-2007$ & 9784 & 13,876 & 23,660 & 2.59 & 3.20 & 4.09 \\
\hline Turin A & 2666 & 2004 & 424,872 & 45 & 96 & 165 & 467,276 & 50 & 107 & 182 & $1995-2008$ & 14,079 & 21,133 & 35,212 & 5.02 & 6.58 & 7.84 \\
\hline Turin $B^{e}$ & 94 & 2004 & 424,872 & 166 & 5,411 & 9,981 & 467,276 & 211 & 4,895 & 9,238 & $1995-2008$ & 14,079 & 21,133 & 35,212 & 4.96 & 6.26 & 8.00 \\
\hline Zurich & 212 & 2004 & 177,970 & 497 & 801 & 1119 & 187,007 & 489 & 842 & 1214 & 1995-2008 & 3701 & 5992 & 9693 & 4.49 & 6.16 & 7.52 \\
\hline
\end{tabular}

a Causes of death included and their ICD-10 codes are: AIDS/HIV disease (B20-B24, R75), MN colon (C18), MN rectum, anus, anal canal (C19-C21), MN cervix uteri (C53), MN testes (C62), Hodgkin's disease (C81),

Rheumatic heart disease (100-109), Hypertension (110-113), Heart failure (150-151), Cerebrovascular diseases (160-169), Peptic ulcer (K25-K27), Renal failure (N17-N19),

Conditions originating in the perinatal period (P00-P96), Congenital heart disease (Q20-Q24).

"For Brussels we analyzed "Brussels Region".

"For Lisbon we analyzed "Lisbon Metropolitan Area".

${ }^{\mathrm{d}}$ The analysis for London does not include mortality from Conditions originating in the perinatal period and Congenital heart disease because these causes of death were not reported in the mortality data.

${ }^{\mathrm{e}}$ This second setup for Turin is used in a sensitivity analysis, see discussion. 
The first column shows that the number of areas differs greatly between cities, between 17 relatively large areas in Bratislava and 2666 very small areas in Turin. The distribution of social deprivation in the last three columns is also different across cities, e.g. Brussels, London and Rotterdam show higher proportions of deprived areas than Bratislava, Prague or Stockholm. Cause-specific numbers of death are in the appendix [see additional file 1].

Due to space limitations we can only show mortality maps for two out of 15 cities in Figure 1. The remaining maps for avoidable mortality are in the appendix [see additional file 2] and also the cause-specific maps [see additional files 3 , additional file 4, additional file 5 , additional file 6 , additional file 7 , additional file 8 , additional file 9 , additional file 10 , additional file 11 , additional file 12 , additional file 13 , additional file 14 , additional file 15 , additional file 16 and additional file 17]. Figure 1 shows that mortality from avoidable causes shows a clear spatial pattern in both cities. In
Lisbon small areas with significantly higher mortality (dark brown) are in the very center of the city, while there is lower mortality mainly in the north-west but also in the south (green). In London however, the city center is characterized by lower mortality, and the areas with lower mortality extend more to the West, East and South for men than for women. All areas at the edge of London show higher mortality except for the West. In summary, Lisbon has a city center with relatively high mortality and the center of London has relatively low mortality. In both cities disadvantaged areas are larger for men than for women. The relative mortality level with respect to the EU average can be better displayed in the box-plots presented in the next section.

Figure 2 provides box-plots for all 15 cities for men and women respectively. Cities with a mortality level clearly below the EU average tend to be in Central and Northern Europe (mainly Amsterdam, Brussels, Helsinki, London,

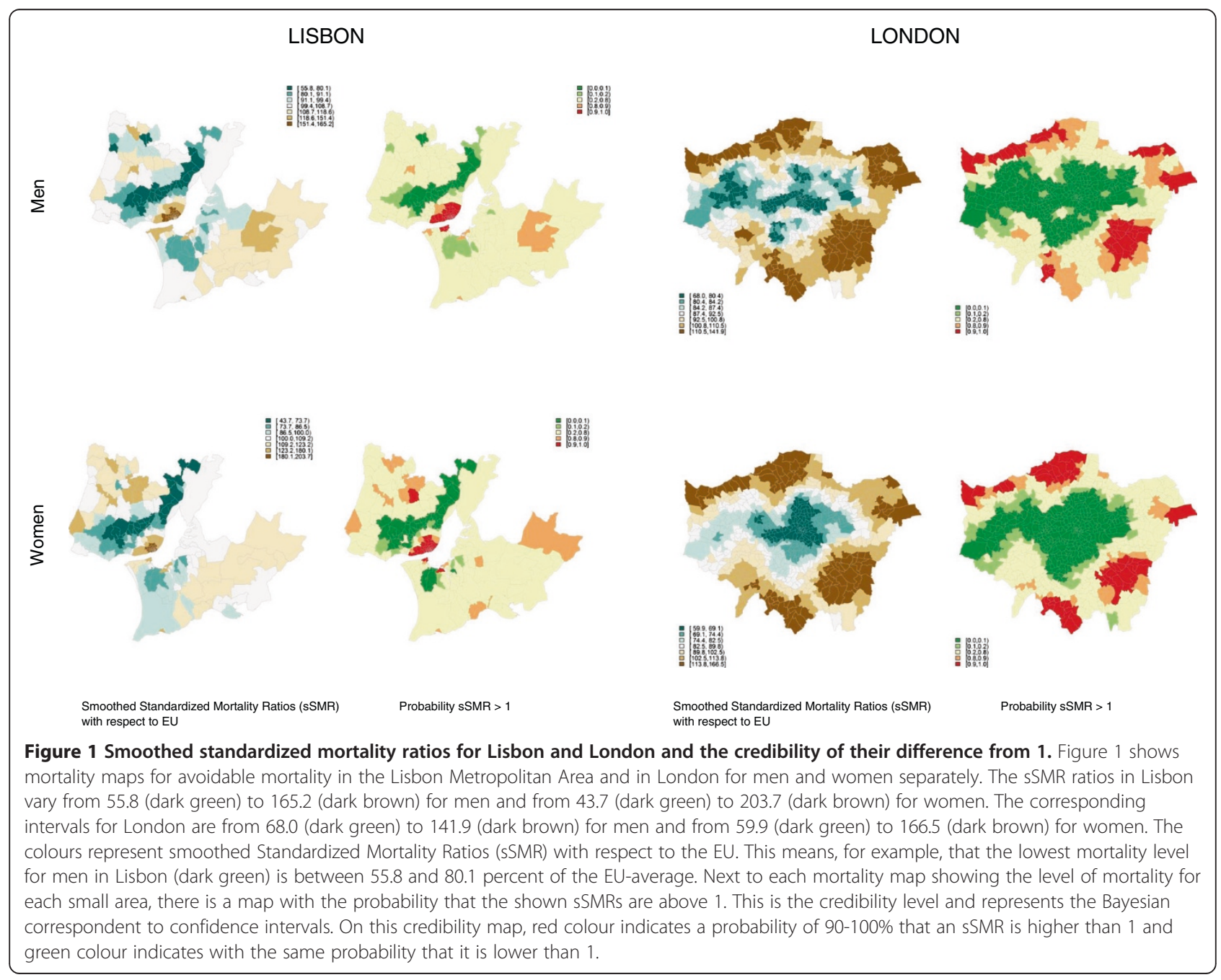




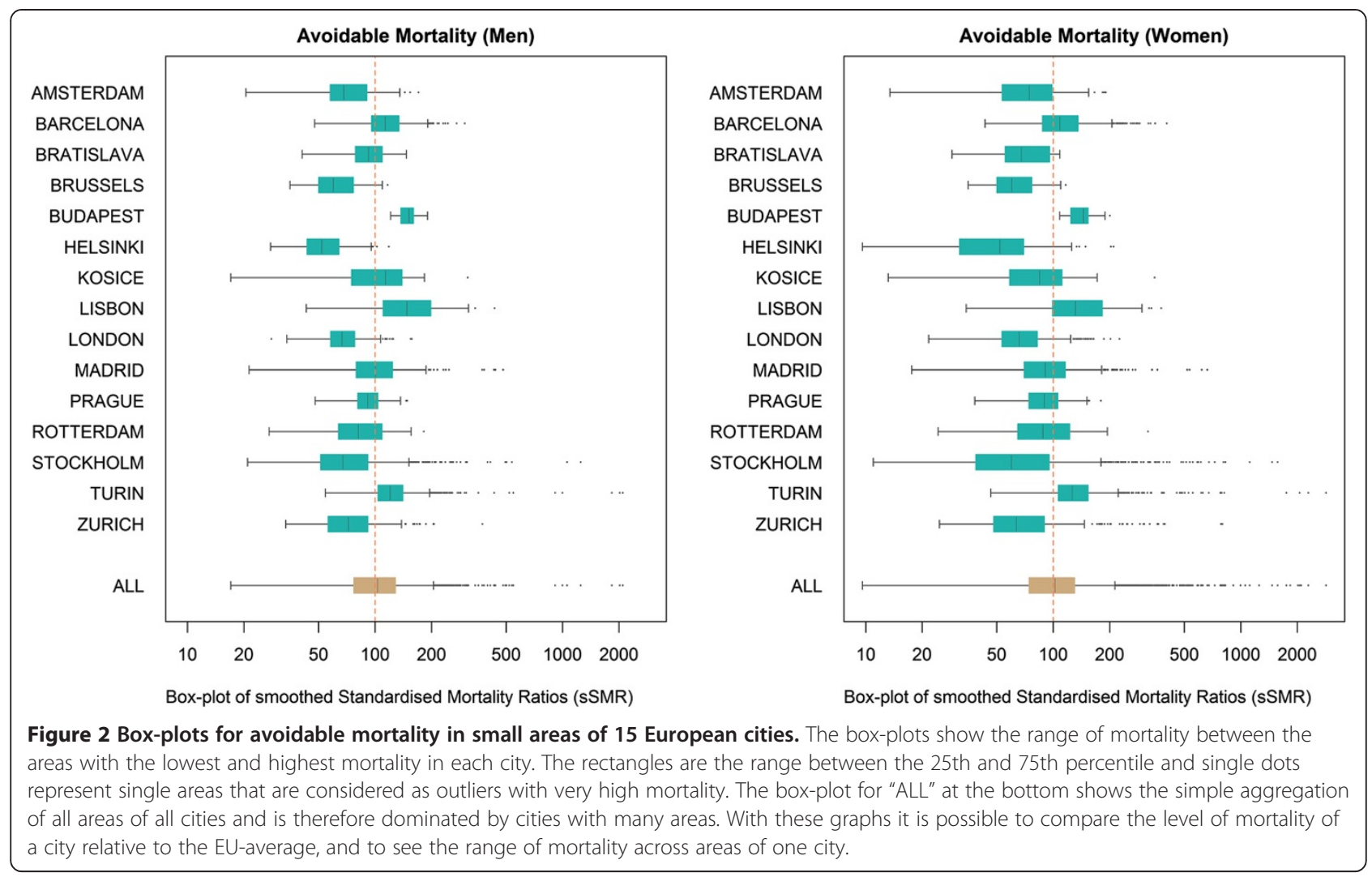

Stockholm and Zurich) while cities with high mortality are in the East and in the South (mainly Budapest, Lisbon, Turin). This pattern is generally true for both men and women with the exception of Bratislava where female avoidable mortality is well below the EU average. Women show wider ranges of mortality across areas in almost all cities. The cause-specific box-plots are shown in the appendix [see additional file 18].

Figure 3 presents the results of the ecological regression of mortality on social deprivation exploring the association between the index of social deprivation and avoidable mortality. Most rate ratios in Figure 3 and all statistically significant rate ratios indicate a positive association between area deprivation and avoidable mortality. However there is also a considerable number of rate ratios below 1 , albeit not statistically significant. The excess risk of mortality is not significantly different between men and women, although in most cities there is a higher association for men than for women. The international comparison across European regions shows a slight tendency towards higher rate ratios in Northern Europe and low rate ratios in Southern Europe. But overall, we do not find a systematic pattern in the magnitude of health inequality between European regions or cities. The cause-specific rate ratios are presented in the appendix as a table [see additional file 19] and as graphs [see additional file 20].

\section{Discussion}

This study is the first that offers an international comparison of avoidable mortality at the small area level and its association with social deprivation of the area. Our results show that there are significant differences in the level of avoidable mortality between neighbourhoods. We showed that higher and lower levels of mortality cluster into a geographical pattern across the city area, such as center versus periphery, or north, south, east or west. Mortality from avoidable causes of death is often but not always higher in deprived areas with higher social differences among men than among women. We could not identify cities, countries or European regions that consistently show higher or lower health inequality.

We also cannot confirm findings from previous studies that larger cities are more unequal [27].

Our findings can extend the current knowledge by showing spatial patterns of avoidable mortality in many cities of several European countries, identifying small areas in each city with an excess risk of avoidable mortality and thereby pointing at problematic areas that could potentially benefit from urban policies addressing 


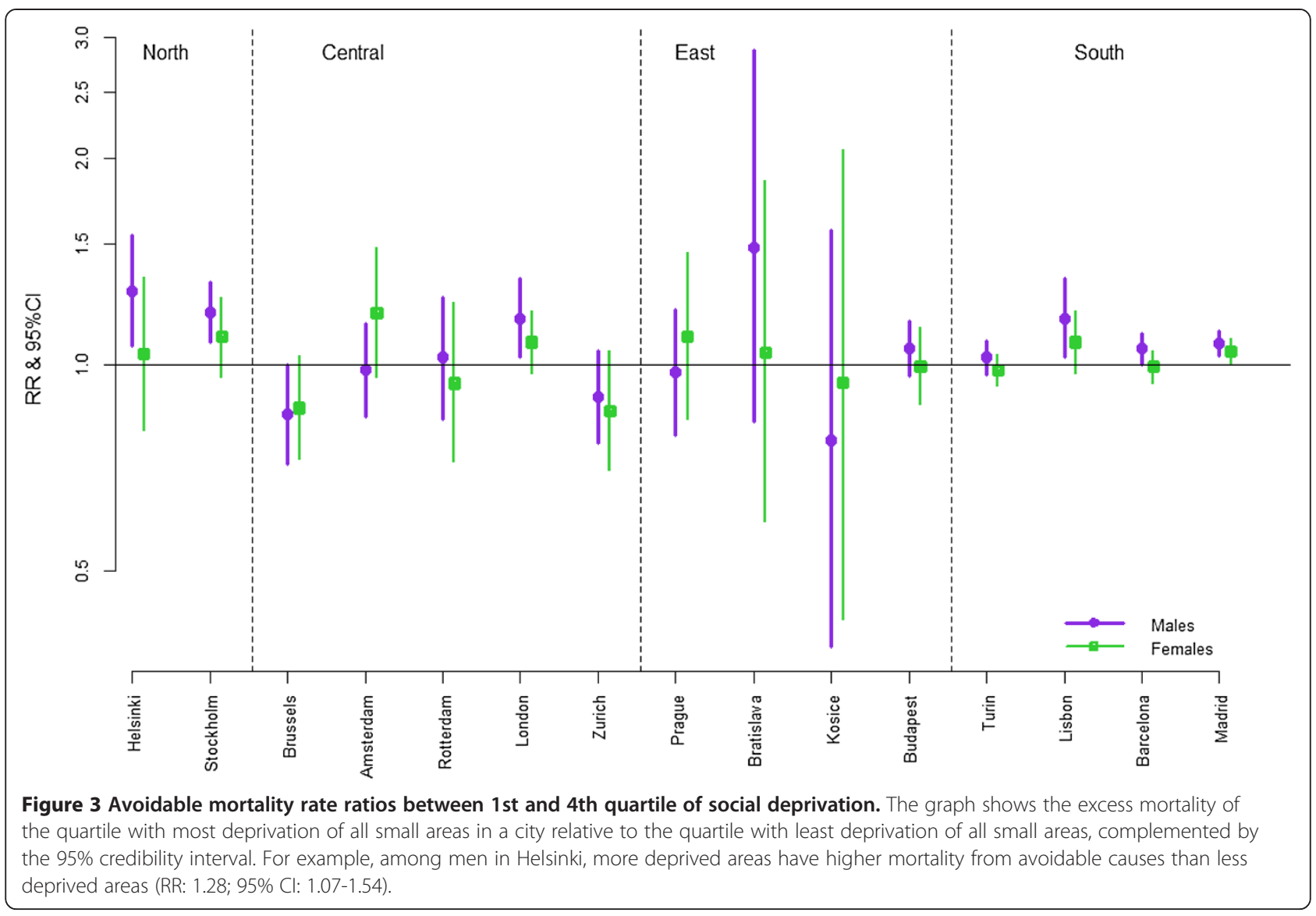

avoidable causes of death and social inequalities in these deaths. Because the use of the concept of avoidable mortality is always dependent on how avoidability is defined it is important to note that our selection of causes of death includes deaths that can be avoided by medical care and not by health care or social policy in a wider sense.

The results from our international comparison across Europe cannot be directly compared to previous findings because our study is the first to provide such results. However, the lack of a strong pattern of different magnitudes of health inequalities between different regions of Europe is surprising and requires some tentative explanations because at the individual level the magnitude of health inequality differs across countries and European regions. One previous study compared the effect of small area unemployment on all-cause mortality between cities from six different countries [28]. The authors concluded that this effect is not substantially modified by the country, although one could have expected such international differences based on differences in absolute levels (and ranges) of deprivation or based on different national policies to address health inequalities. We tend to agree to their interpretation that there seems to be a general mechanism that links area level deprivation to mortality across many European cities, either because these cities are not different enough, or because they are just similar social worlds of relative social deprivation and its effect on health.

\section{Limitations}

One major limitation is the low statistical power of our analysis that focuses on numbers of deaths in relatively small areas. Credibility intervals are large and in the cause-specific analysis presented in the appendix, several cases had to be excluded due to too many areas with zero deaths [29]. This makes it difficult to systematically compare cause-specific results between cities and it was the reason to let the main part of the study focus on the 14 aggregated causes of death in order to draw general conclusions on avoidable mortality. The problem of low numbers of death can hardly be avoided if one wants to look at mortality in small areas, because, first, larger areas would increase the heterogeneity within each area in terms of deprivation and mortality and, second, a longer period of observation over which rare deaths could be aggregated would necessarily introduce more bias 
from migration, changing borders between small areas and other changes over time. To obtain acceptable numbers of death we had to aggregate mortality data from several years which assumes that other circumstances such as migration and consequent change of the exposed population are negligible and do not bias the results substantially $[30,31]$

Second, the number of areas differs greatly between cities. The median population size per area varies between about 100 persons in Turin and about 40,000 in Budapest (Table 1). Smaller areas tend to be more homogeneous and the result is potentially higher variability between the areas. This influences the variance in the deprivation index between areas. Differences in observed SMRs could also be dampened as higher concentrations of mortality in smaller areas will dissolve in larger areas. Inversely, more extreme variance in SMRs could appear by using smaller areas. As a consequence, the comparison between cities could be difficult, because the observed variance is a result both of bigger disparities in social status and of the area size. However, our method takes into account this effect by controlling for spatial dependence of small areas, that is to say for similarities of neighbouring areas. This results in clustering of similar small areas. In fact, previous studies have shown that the bias due to different level of units within a city is relatively small [32]. We also examined this possible bias by a sensitivity analysis in which we used an alternative division into fewer areas for Turin, the city with the smallest areas in our study. In the original analysis Turin had 2666 small areas and the second available official division from the city of Turin has 94 areas. These two alternative setups are presented in Table 1 . The result of this sensitivity analysis is that the rate ratios for the effect of deprivation on avoidable mortality changed from 1.02 (CI: 0.97-1.09) and 0.98 (CI: $0.93-1.04$ ) to 0.99 (CI: 0.77-1.05) and 1.08 (CI: 0.90-1.30) for men and women respectively. While the point estimates hardly change, the confidence intervals become wider due to fewer areas. More importantly, we do not see lower rate ratios as could be expected with fewer areas, but rather the opposite. Turin was the only city where an alternative division into areas was available and we conclude that our overall results and conclusions are not sensitive to the number of areas. Maps for avoidable mortality for Turin with 2666 and 94 areas can be found in the appendix [see additional file 2].

Next to these limitations we can point at exceptional strengths. First, we created a unique data collection on cause-specific mortality data on the small area level of 15 European cities and on several indicators of social deprivation of these areas. Second, these indicators were the same across all cities of all countries, and by that we solved a common problem in international comparative studies of health inequalities. Third, we used a powerful and established analytic method for the ecological analysis of the association between deprivation and mortality level. This method allows producing smoothed estimates based on relatively low number of cause-specific deaths in small areas, minimizing potential bias, and still presenting a valid spatial pattern in each city. The appropriateness of Bayesian hierarchical modelling for this purpose is widely recognized [33].

\section{Conclusions}

Our study shows clear differences in the level of avoidable mortality between neighbourhoods of European cities and the level of avoidable mortality is in general positively associated with social deprivation. There is no systematic difference in the magnitude of this association between European cities or regions. It is important to monitor avoidable mortality on the level of small areas because they have the potential to point to specific areas with need for specific medical care and they also reflect inequalities with regard to medical care at the individual level. But without sufficient data on medical care services on the city and on the small area level, it is very difficult to conclude from the mortality level in a small area to specific problems. Therefore, cause-specific mortality maps can only be used to point at potential problems in deprived small areas, which then have to be studied with more specific information and better local data on the relation between medical care and health outcome.

\section{Methods}

Based on previous work on avoidable causes of death, we selected 14 causes of death amenable to medical intervention (see footnote in Table 1) [34]. This selection covers causes of death amenable to primary and secondary prevention (e.g. vaccination, cancer screening) as well as causes of death amenable to treatment (e.g. surgery, chemotherapy), but not deaths avoided by health policy in general, e.g. tobacco control. Our choice is restricted to causes of death for which numbers can be expected to be large enough to allow small area analysis.

The data we use for this analysis are, first, mortality data by cause of death aggregated during a period of several years around the year 2001 (see Table 1), by age, gender and small area for 15 European cities from the respective national statistical offices, and second, information on several social indicators from censuses around the year 2001, except for the two Dutch cities where a labour force survey was used. The 15 cities represent four main European regions (north, central, east, south). The expected numbers of deaths in each area of the cities were calculated with the population in the whole period (although for some cities the population in one year was multiplied by the years in the study period) and taking as reference mortality rates by gender, age (5 year age-specific mortality rates) and 
cause of death in 25 countries that were part of the 27 countries of the European Union in 2004 [35].

\section{Index of deprivation}

When constructing the index of deprivation, we used five socioeconomic indicators: percentage of unemployed persons, percentage of manual workers, percentage of population aged 25-64 with primary education or lower, percentage of population aged 25-34 with a university degree, and percentage foreigners from low income countries. These indicators were selected out of a set of 13 indicators for social status available in our dataset. Of the eight indicators discarded, two indicators related to lower education were removed for conceptual reasons. In the case of the percentage of people with primary education or lower, we preferred to use the 25-64 age range (instead of the 25-34 age range) because six cities did not have data for the 2534 age group. Two age ranges for percentage of people with a university degree were available in most of the cities. In this case, we chose the indicator measuring the percentage in the 25-34 age range, because access to university was very low in the age range 25-64. Two indicators were discarded because they barely contributed anything to the percentage of variance explained by the five indicators finally chosen: activity rate of the population and non-home ownership. The indicators that reflected the percentage of temporary workers or the percentage of part-time workers were excluded due to lack of information in some cities (nine cities in the case of temporary contracts and five in the case of part time work) and also because in most cities such working conditions were not directly related to deprivation but rather depended on the country's labour market conditions. In fact, the correlations between unemployment (which is commonly regarded as the most important indicator for social deprivation) and these two variables were relatively small $(0.328$ for temporary workers and 0.121 for part-time workers), especially for women working part-time (0.081). The reasons for the exclusion of the variables indicating single parent households and overcrowding were similar: neither seems to be clearly related to deprivation. The correlation with unemployment was either very small (0.061 for overcrowding) or even negative (-0.106 for single parent household).

The deprivation index was constructed by aggregating the above-mentioned variables using the distance indicator, $\mathrm{DP}_{2}$ [36]. This indicator permits to obtain an index that is comparable across cities. Albeit not carrying out the widely used principal component analysis (PCA) $[37,38]$, the original variables we used are very similar to other small area studies [25,27]. Let $\mathrm{x}_{\mathrm{i}}$ be the vector of the state of the components (indicators) in the situation $\mathrm{i}$, and $\mathrm{x}_{\mathrm{ij}}$ be the state of the component $\mathrm{j}$ in situation i. Let $\mathrm{x}_{\mathrm{i}^{*}}$ be the reference vector. This vector can represent an ideal situation where $x_{i^{*} j}$ is the state of component $\mathrm{j}$ in the reference situation. In order to compare $\mathrm{x}_{\mathrm{i}}, \mathrm{x}_{\mathrm{i}^{*}}$ the $\mathrm{DP}_{2}$ index is defined in the following manner:

$$
D P_{2}=\sum_{j=1}^{p} \frac{\left|x_{i j}-x_{i^{*} j}\right|}{\sigma_{j}}\left(1-R_{j, j-1, j-2, \ldots, 1}^{2}\right)
$$

Where $R_{j, j-1, j-2, \ldots, 1}^{2}$ is the coefficient of determination in the regression of $x_{j}$ over $x_{j-1}, x_{j-2}, \ldots, x_{1}$. This coefficient is independent of the unit of measure of the variables. $R_{1}^{2}=0$, given that the first variable contributes all its information as there is no previous variable, and the weight assigned to it is 1 . The standard deviation $\sigma_{j}$ corresponds to the component $\mathrm{j}$. Dividing the distance for component $j$ by $\sigma_{j}$ the indicator is dimensionless. Moreover, this distance is weighted by the inverse of $\sigma_{j}$, so that its contribution to the index is inversely proportional to its dispersion. The main weights are given by $\left(1-R_{j, j-1, j-2, \ldots, 1}^{2}\right)$. These factors eliminate the redundant information of the indicators, separating these from the variability already explained by other preceding indicators. The $\mathrm{DP}_{2}$ is constructed following an iterative procedure. The order in which the indicators are introduced alters the final result. In order to control this, the iterative process of Ivanovic is applied [39]. Each indicator is introduced according to its linear correlation previously calculated. Iteration continues until the order of the indicators is stabilized. The final $\mathrm{DP}_{2}$ distance for case $i$ with respect to reference $i *$ (which is the most favourable value for each indicator) shows the correct order of inclusion for the indicators [36]:

$$
\begin{aligned}
D P_{2}= & \frac{\left|x_{i 1}-x_{i^{*} 1}\right|}{\sigma_{1}}+\frac{\left|x_{i 2}-x_{i^{*} 2}\right|}{\sigma_{2}}\left(1-R_{2,1}^{2}\right) \\
& +\frac{\left|x_{i 3}-x_{i^{*} 3}\right|}{\sigma_{3}}\left(1-R_{3,2,1}^{2}\right)+\ldots \\
& +\frac{\left|x_{i p}-x_{i^{*} p}\right|}{\sigma_{p}}\left(1-R_{p, p-1, \ldots, 1}^{2}\right)
\end{aligned}
$$

\section{Standardised mortality ratios}

Our mortality maps show Standardized Mortality Ratios (SMR) which are expressed as [observed cases/expected cases]*100. When analysing aggregated data from small areas of a city it is important to account for two sources of variability: first, the spatial dependence between geographical areas, which means that neighbouring areas are more likely to have a similar deprivation and mortality level than distant areas; second, the non-spatial variability (random variation). To solve the problems associated with SMRs for small areas with low number of deaths we smooth them using the Bayesian model proposed by Besag, York and Mollié (BYM-model) [40] 
obtaining smoothed SMR (sSMR). The geographical distributions of SSMR values derived from the BYM models are displayed using maps of the septiles of the sSMR. Areas with dark green colours have the lowest sSMR and those with dark brown tones have the highest. The model used was:

$$
\begin{aligned}
& O_{i} \sim \operatorname{Poisson}\left(E_{i} \theta_{i}\right) \\
& \log \left(\theta_{i}\right)=\alpha+S_{i}+H_{i}
\end{aligned}
$$

$O_{i}$ denoted the observed cases of deaths for a particular cause and gender in the small area $\mathrm{i}$ of a city; $E_{i}$ was the expected number of deaths (of such cause and gender) in the small area $\mathrm{i}$, and $\theta_{i}$ the relative risk for each specific area. $\alpha$ represents the intercept, $\mathrm{S}_{\mathrm{i}}$ spatial random effects and $\mathrm{H}_{\mathrm{i}}$ denotes heterogenous (non-spatial) effects.

In the mortality maps, for each city, the sSMR for each area were estimated as follows:

$$
s S M R_{-i(c)}=\exp \left(S_{i}+H_{i}\right)
$$

In the box-plots showing the range of mortality across small areas for each city, the sSMR for each area were estimated as follows:

$$
s S M R_{-i(e u)}=\exp \left(\alpha+S_{i}+H_{i}\right)
$$

Note that the sSMRs for the mortality maps exclude the intercept of the Poisson model $\alpha$ in order to be comparable to the average mortality level of the city (indicated by the subscript c), while the sSMRs for the box-plots include the intercept and thereby refer to the European mortality level (indicated by the subscript eu).

\section{Ecological regression}

We analysed how the cause-specific level of mortality in a small area is associated with the degree of social deprivation. In each of the cities, for each of the causes of death and for each gender, the observed cases of death were assumed to follow a Poisson distribution,

$$
O_{i} \sim \operatorname{Poisson}\left(\mu_{i} E_{i}\right)
$$

where $\mu_{\mathrm{i}}$ was the relative risk in the small area i. In turn, the relative risk could be associated with the explanatory variables by means of an ecological regression. In our case, this regression was formulated as follows:

$$
\log \left(\mu_{i}\right)=\alpha+\sum_{j=2}^{4} \beta_{j} X Q_{j, i}+S_{i}+H_{i}
$$

where $\mathrm{XQ}_{\mathrm{j}, \mathrm{i}}$ denoted the $\mathrm{j}$-th quartile of the socioeconomic indicator $\mathrm{X}$ (the quartiles were constructed within each city) - the first quartile (corresponding to the lowest deprivation) was taken as a reference value - and $\alpha$ and the $\beta$ s were unknown parameters.

We were interested in the relative risk associated with each quartile of the socioeconomic indicator, i.e. $e^{\beta_{2}}$ for the second quartile; $e^{\beta_{3}}$ for the third quartile and $e^{\beta_{4}}$ for the fourth quartile (always with respect to the first quartile). However, in the result section we only present rate ratios for the fourth quartile (most deprived) relative to the first (least deprived). Using quartiles of the city specific social distribution of small areas implies that our measure of deprivation is a relative measure. No absolute categories of social deprivation were applicable across 15 cities of different European countries and regions.

The deprivation index was included in quartiles in the ecological regressions for two reasons: first, to capture a possible nonlinear relationship between the indicators (including the deprivation index) and the response variable, second, to avoid the effects of concurvity, the non-linear analogue of multi-collinearity, as a consequence of a high correlation between the covariates and the clustering term. The ecological associations we present are likely to represent both the effect of individual level socioeconomic status on health and the effect of the area level social deprivation, which again can consist of social and physical pathways. We used the software WinBUGS and the $\mathrm{R}$ statistical package. All maps are plotted using $\mathrm{R}$ and we have used a diverging color scheme brown/blue-green which has been shown to be an effective choice of pair hues for the representation of mortality ratios on choropleth maps [41].

\section{Additional files}

Additional file 1: Cause-specific numbers of death.

Additional file 2: Avoidable mortality maps for remaining 13 cities.

Additional file 3: Cause-specific mortality maps for Amsterdam.

Additional file 4: Cause-specific mortality maps for Barcelona.

Additional file 5: Cause-specific mortality maps for Bratislava.

Additional file 6: Cause-specific mortality maps for Brussels.

Additional file 7: Cause-specific mortality maps for Budapest.

Additional file 8: Cause-specific mortality maps for Helsinki.

Additional file 9: Cause-specific mortality maps for Kosice.

Additional file 10: Cause-specific mortality maps for Lisbon.

Additional file 11: Cause-specific mortality maps for London.

Additional file 12: Cause-specific mortality maps for Madrid.

Additional file 13: Cause-specific mortality maps for Prague.

Additional file 14: Cause-specific mortality maps for Rotterdam.

Additional file 15: Cause-specific mortality maps for Stockholm.

Additional file 16: Cause-specific mortality maps for Turin.

Additional file 17: Cause-specific mortality maps for Zurich.

Additional file 18: Cause-specific box-plots graphs.

Additional file 19: Cause-specific mortality rate ratios (Table).

Additional file 20: Cause-specific mortality rate ratios (Graphs). 


\section{Competing interests}

The authors declare that they have no competing interests.

\section{Authors' contributions}

$\mathrm{RH}$ drafted the paper, made the main conception and design of the paper and interpretation of data, and contributed to the analysis. GB, MS, MMDO made or contributed to data analysis and interpretation and revised the paper. CB, JMo, JMa have contributed to conception and design and interpretation of data and revised the paper. BB, DC, CC, PD, FD, DD, AG, MG, KK, PM, LP, GP, HP, MRS, PS, LT prepared data for the analysis and revised the paper. LMP, CS contributed to data analysis and revised the paper. All authors read and approved the final manuscript.

\section{Author details}

'Department of Public Health, Erasmus Medical Center, P.O. Box 2040, Rotterdam, CA 3000, The Netherlands. ${ }^{2}$ Research Group on Statistics, Econometrics and Health (GRECS), University of Girona, Campus de Montilivi, Girona 17071, Spain. ${ }^{3}$ CIBER of Epidemiology and Public Health (CIBERESP), Madrid, Spain. ${ }^{4}$ Department of Public Health Sciences, Division of Social Medicine, Karolinska Institutet, Stockholm 17177, Sweden. ${ }^{5}$ Centro de Estudos de Geografia e de Ordenamento do Territorio (CEGOT), Departamento de Geografia, Colégio de S. Jerónimo, Universidade de Coimbra, Coimbra 3000-043, Portugal. ${ }^{6}$ Department of Social research, Vrije Universiteit Brussel, Pleinlaan 2, Elsene, Brussels 1050, Belgium. ${ }^{7}$ Subdirección de Promoción de la Salud y Prevención. Consejería de Sanidad, San Martín de Porres, 6, 28035, Madrid 28037, Spain. ${ }^{8}$ Department of Social Geography and Regional Development, Faculty of Science, Charles University in Prague, Albertov 6, Prague 2 12843, Czech Republic. 'Demographic Research Institute, HCSO, 1024, 1/3 Buday L. u., Budapest, Hungary. ${ }^{10}$ Department of Social Research, University of Helsinki, P.O. Box 18, Helsinki 00014, Finland.

${ }^{11}$ London School of Hygiene and Tropical Medicine, London, UK. ${ }^{12}$ Department of Epidemiology and Public Health, University College London, 1-19 Torrington Place, London WC1E 6BT, United Kingdom. ${ }^{13}$ Agència de Salut Pública de Barcelona, Plaça Lesseps, 1, Barcelona 08023, Spain.

Received: 15 January 2014 Accepted: 3 March 2014

Published: 12 March 2014

\section{References}

1. Rutstein DD, Berenberg W, Chalmers TC, Child CG 3rd, Fishman AP, Perrin EB: Measuring the quality of medical care. A clinical method. N Engl J Med 1976, 294:582-588.

2. Rutstein DD, Berenberg W, Chalmers TC, Child CG 3rd, Fishman AP, Perrin EB: "Measuring the quality of medical care": revision of tables of indexes. N Engl J Med 1977, 297:508.

3. Rutstein DD, Berenberg W, Chalmers TC, Fishman AP, Perrin EB, Zuidema GD: Measuring the quality of medical care: second revision of tables of indexes. N Engl J Med 1980, 302:1146.

4. Charlton JR, Hartley RM, Silver R, Holland WW: Geographical variation in mortality from conditions amenable to medical intervention in England and Wales. Lancet 1983, 1:691-696.

5. Holland W: European Community Atlas Of 'Avoidable Death' 1985-89. Oxford: Oxford University Press; 1997.

6. Tobias M, Jackson G: Avoidable mortality in New Zealand, 1981-97. Aust N Z J Public Health 2001, 25:12-20.

7. Albert X, Bayo A, Alfonso JL, Cortina P, Corella D: The effectiveness of health systems in influencing avoidable mortality: a study in Valencia, Spain, 1975-90. J Epidemiol Community Health 1996, 50:320-325.

8. Carr-Hill RA, Hardman GF, Russell IT: Variations in avoidable mortality and variations in health care resources. Lancet 1987, 1:789-792.

9. Mackenbach JP, Bouvier-Colle MH, Jougla E: "Avoidable" mortality and health services: a review of aggregate data studies. J Epidemiol Community Health 1990, 44:106-111.

10. Mackenbach JP, Hoffmann R, Khoshaba B, Plug I, Rey G, Westerling R, Paerna K, Jougla E, Alfonso J, Looman C, McKee M: Using 'amenable mortality' as indicator of healthcare effectiveness in international comparisons: results of a validation study. J Epidemio/ Community Health 2013, 67:139-146.

11. Mackenbach JP: An analysis of the role of health care in reducing socioeconomic inequalities in health: the case of the Netherlands. Int J Health Serv 2003, 33:523-541.
12. Mackenbach JP, Stronks K, Kunst AE: The contribution of medical care to inequalities in health - differences between socioeconomic groups in decline of mortality from conditions amenable to medical intervention. Soc Sci Med 1989, 29:369-376.

13. Stirbu I, Kunst AE, Mielck A, Mackenbach JP: Inequalities in utilisation of general practitioner and specialist services in 9 European countries. BMC Health Serv Res 2011, 11.

14. Stirbu I, Kunst AE, Bopp M, Leinsalu M, Regidor E, Esnaola S, Costa G, Martikainen P, Borrell C, Deboosere P, Kalediene R, Rychtarikova J, Artnik B, Mackenbach JP: Educational inequalities in avoidable mortality in Europe. Journal of Epidemiology and Community Health 2010, 64:913-920.

15. Plug I, Hoffmann R, Artnik B, Bopp M, Borrell C, Costa G, Deboosere P, Esnaola S, Kalediene R, Leinsalu M, Lundberg O, Martikainen P, Regidor E, Rychtarikova J, Strand B, Wojtyniak B, Mackenbach JP: Socioeconomic inequalities in mortality from conditions amenable to medical interventions: do they reflect inequalities in access or quality of health care? BMC Public Health 2012, 12.

16. Cummins S, Curtis S, Diez-Roux AV, Macintyre S: Understanding and representing 'place' in health research: a relational approach. Soc Sci Med 1825-1838, 2007:65.

17. Macintyre S, Ellaway A, Cummins S: Place effects on health: how can we conceptualise, operationalise and measure them? Soc Sci Med 2002, 55:125-139.

18. Vlahov D, Freudenberg N, Proietti F, Ompad D, Quinn A, Nandi V, Galea S: Urban as a determinant of health. J Urban Health 2007, 84:116-26.

19. WHO/UN-HABITAT: Hidden Cities: Unmasking And Overcoming Health Inequalitiesin Urban Settings. Geneva: World Health Organization; 2010.

20. Diez Roux AV, Mair C: Neighborhoods and health. Ann N Y Acad Sci 2010, 1186:125-145.

21. Borrell C, Pasarin Ml: Inequalities in health and urban areas. Gac Sanit 2004, 18:1-4.

22. Auchincloss AH, Gebreab SY, Mair C, Roux Diez AV: A review of spatial methods in epidemiology, 2000-2010. Annu Rev Public Health 2012, 33:107-122.

23. Bithell JF: A classification of disease mapping methods. Stat Med 2000, 19:2203-2215.

24. Mackenbach JP, Kunst AE, Looman CW, Habbema JD, van der Maas PJ: Regional differences in mortality from conditions amenable to medical intervention in The Netherlands: a comparison of four time periods. J Epidemiol Community Health 1988, 42:325-332.

25. Nolasco A, Melchor I, Pina JA, Pereyra-Zamora P, Moncho J, Tamayo N, Garcia-Senchermes C, Zurriaga O, Martinez-Beneito MA: Preventable avoidable mortality: evolution of socioeconomic inequalities in urban areas in Spain, 1996-2003. Health Place 2009, 15:702-711.

26. James PD, Wilkins R, Detsky AS, Tugwell P, Manuel DG: Avoidable mortality by neighbourhood income in Canada: 25 years after the establishment of universal health insurance. J Epidemiol Community Health 2007, 61:287-296.

27. Borrell C, Mari-Dell'Olmo M, Serral G, Martinez-Beneito M, Gotsens M, Members M: Inequalities in mortality in small areas of eleven Spanish cities (the multicenter MEDEA project). Health Place 2010, 16:703-711.

28. van Lenthe FJ, Borrell LN, Costa G, Roux AVD, Kauppinen TM, Marinacci C, Martikainen P, Regidor E, Stafford M, Valkonen T: Neighbourhood unemployment and all cause mortality: a comparison of six countries. J Epidemiol Community Health 2005, 59:231-237.

29. Barcelo AM, Saez M, Cano-Serral G, Angel Martinez-Beneito M, Miguel Martinez J, Borrell C, Ocana-Riola R, Montoya I, Calvo M, Lopez-Abente G, Rodríguez-Sanz M, Toro S, Tomás Alcalá J, Saurina C, Sánchez-Villegas P, Figueiras A: Methods to smooth mortality indicators: application to analysis of inequalities in mortality in Spanish cities the MEDEA Project. Gaceta Sanitaria 2008, 22:596-608.

30. Ocana-Riola R: The misuse of count data aggregated over time for disease mapping. Stat Med 2007, 26:4489-4504.

31. Ocana-Riola R, Fernandez-Ajuria A, Maria Mayoral-Cortes J, Toro-Cardenas S, Sanchez-Cantalejo C: Uncontrolled migrations as a cause of inequality in health and mortality in small-area studies. Epidemiology 2009, 20:411-418.

32. Tarkiainen $L$, Martikainen $P$, Laaksonen M, Leyland AH: Comparing the effects of neighbourhood characteristics on all-cause mortality using two hierarchical areal units in the capital region of Helsinki. Health Place 2010, 16:409-412.

33. Graham P: Intelligent smoothing using hierarchical Bayesian models. Epidemiology 2008, 19:493-495.

34. Hoffmann R, Plug I, Khoshaba B, McKee M, Mackenbach JP: Amenable mortality revisited; the AMIEHS study. Gac Sanit 2013, 27:199-206.

35. European Detailed Mortality Database (DMDB). [http://www.euro.who.int/en/ what-we-do/data-and-evidence/mortality-database-updated] 
36. Salcedo N, Saez M, Bragulat B, Saurina C: Does the effect of gender modify the relationship between deprivation and mortality? BMC Public Health 2012, 12.

37. Deguen S, Lalloue B, Bard D, Havard S, Arveiler D, Zmirou-Navier D: A small-area ecologic study of myocardial infarction, neighborhood deprivation, and sex a Bayesian modeling approach. Epidemiology 2010, 21:459-466.

38. Sullivan AB, Gesink DC, Brown P, Zhou L, Kaufman JS, Fitch M, Serre ML, Miller WC: Are neighborhood sociocultural factors influencing the spatial pattern of gonorrhea in north Carolina? Ann Epidemiol 2011, 21:245-252.

39. Ivanovic B: Comment établir une liste des indicateurs de développement. Rev Stat Appl 1974, 22:37-50

40. Besag J, York J, Mollie A: Bayesian image-restoration, with two applications in spatial statistics. Ann Inst Stat Math 1991, 43:1-20

41. Brewer CA, MacEachren AM, Pickle LW, Herrmann D: Mapping mortality: evaluating color schemes for choropleth maps. Ann Assoc Am Geogr 1997, 87:411-438

doi:10.1186/1476-072X-13-8

Cite this article as: Hoffmann et al: Social differences in avoidable mortality between small areas of 15 European cities: an ecological study. International Journal of Health Geographics 2014 13:8.

\section{Submit your next manuscript to BioMed Central and take full advantage of:}

- Convenient online submission

- Thorough peer review

- No space constraints or color figure charges

- Immediate publication on acceptance

- Inclusion in PubMed, CAS, Scopus and Google Scholar

- Research which is freely available for redistribution 